\title{
Pengaruh Jumlah Katup Hisap dan Katup Buang Terhadap Kinerja Pompa Hidram
}

\author{
Kahar $^{1}$ \\ ${ }^{1}$ Program Studi Teknik Pertanian, Sekolah Tinggi Pertanian KutaiTimur, Sangatta, \\ Kalimantan Timur \\ Email: kahar37@yahoo.co.id
}

\begin{abstract}
The experiment aimed to determined the effect of variations number of valves on hydram pump performance, determined water debit resulting from hydram pump. Research was conducted on April up to June 2016. The data was obtained through the testing will be analyzed by using empirical formulas that support data processing. Research results showed that the efficiency of hydram pump on 1 number of valves 6,0000725\%, 2 number of valves 10,20\%, 3 number of valves 16,0003525\%. Pumping capacity on 1 number of valves $9,2083.10^{-6} \mathrm{~m}^{3} / \mathrm{s}$, 2 number of valves $1,25833.10^{-5}$ $\mathrm{m}^{3} / \mathrm{s}$, 3 number of valves $2,35416.10^{-5} \mathrm{~m}^{3} / \mathrm{s}$. Waste capacity on 1 number of valves $7,25.10^{-5} \mathrm{~m}^{3} / \mathrm{s}$, 2 number of valves $9,41667.10^{-5} \mathrm{~m}^{3} / \mathrm{s}$, 3 number of valves $1,175.10^{-4}$ $\mathrm{m}^{3} / \mathrm{s}$, whereas the capacity total on 1 number of valves $9,09166.10^{-5} \mathrm{~m}^{3} / \mathrm{s}, 2$ number of valves $1,319167.10^{-4} \mathrm{~m}^{3} / \mathrm{s}$, and 3 number of valves $2,116665.10^{-4} \mathrm{~m}^{3} / \mathrm{s}$.
\end{abstract}

Keywords: number of valves, hydram pump, efficiency

\begin{abstract}
ABSTRAK
Penelitian ini bertujuan mengetahui pengaruh pengujian variasi jumlah katup terhadap kinerja pompa hidram, mengetahui debit air yang dihasilkan pada pompa hidram. Penelitian ini dilaksanakan pada bulan April sampai Juni 2016. Data-data yang diperoleh melalui pengujian alat akan dianalisis dengan menggunakan rumus-rumus empiris yang mendukung proses pengolahan data. Hasil penelitian menunjukkan bahwa efisiensi pompa hidram pada jumlah katup 1 buah sebesar $6,0000725 \%$, jumlah katup 2 buah 10,20\%, dan jumlah katup 3 buah 16,0003525\%. Kapasitas pemompaan pada jumlah katup 1 buah 9,2083.10-6 $\mathrm{m}^{3} / \mathrm{s}$, jumlah katup 2 buah $1,25833.10^{-5} \mathrm{~m}^{3} / \mathrm{s}$, dan jumlah katup 3 buah $2,35416.10^{-5} \mathrm{~m}^{3} / \mathrm{s}$. Kapasitas limbah pada jumlah katup 1 buah $7,25.10^{-5} \mathrm{~m}^{3} / \mathrm{s}$, jumlah katup 2 buah $9,41667.10^{-5} \mathrm{~m}^{3} / \mathrm{s}$, dan jumlah katup 3 buah $1,175.10^{-4} \mathrm{~m}^{3} / \mathrm{s}$. Kapasitas total pada jumlah katup 1 buah $9,09166.10^{-5} \mathrm{~m}^{3} / \mathrm{s}$, jumlah katup 2 buah $1,319167.10^{4} \mathrm{~m}^{3} / \mathrm{s}$, dan jumlah katup 3 buah $2,116665.10^{-4} \mathrm{~m}^{3} / \mathrm{s}$.
\end{abstract}

Kata Kunci: Jumlah Katup, PompaHidram, Efisiensi

\section{Pendahuluan}

Negara Indonesia merupakan salah satu negara agraris yang penduduknya hidup dari hasil pertanian, terutama penduduk yang hidupnya di pedesaan. Sebagian besar penduduk yang hidup di pedesaan sumber mata pencahariannya mengandalkan hasil pertanian, perikanan, dan perkebunan. Untuk memperoleh hasil dari pertanian, perikanan, dan perkebunan yang dapat diandalkan, petani harus mengolah lahan tersebut dengan sebaik-baiknya. Untuk mengolah lahan tersebut diperlukan beberapa hal yang dapat mendukung hasil yang optimal, seperti penggunaan alat pengolah tanah (traktor), pemupukan, bibit yang unggul, dan pengairan yang memadai. Banyak lahan pertanian yang letaknya lebih tinggi dari air yang tersedia, sehingga petani akan mengalami kesulitan untuk memperoleh pengairan yang dibutuhkan secara terus menerus. 
Sekarang ini banyak petani yang menggunakan peralatan untuk menaikkan air dari tempat yang lebih rendah ketempat yang lebih tinggi dengan menggunakan mesin dengan bahan bakar bensin atau solar. Karena keadaan geografi dengan kontur yang berbeda-beda elevasinya, menyebabkan daerah yang elevasinya lebih tinggi dari aliran air tidak mendapat pasokkan air secara alami.

Untuk menyelesaikan problem tersebut dapat digunakan pompa yang tidak memerlukan energi luar sebagai sumber tenaga penggerak utama. Pompa Hydraulic Ram (Hidram) adalah sebuah pompa yang tidak memerlukan energi luar sebagai sumber tenaga penggerak utama. Pompa hidram bekerja berdasar prinsip palu air. Ketika air dihentikan secara tiba-tiba, maka perubahan momentum massa fluida tersebut akan meningkatkan tekanan secara tiba - tiba pula. Peningkatan tekanan fluida ini digunakan untuk mengangkat sebagian fluida tersebut ke tempat yang lebih tinggi (Suarda dan Wirawan, 2008).

Salah satu teknologi yang sederhana dan hemat energi dan dapat menaikkan air dari tempat yang rendah ketempat yang tinggi adalah "Pompa Hidram". Pompa hidram atau singkatan dari hidraulik ram berasal dari kata hidro yang berarti air (cairan), ram yang berarti hantaman, pukulan atau tekanan. Jadi, pompa hidram adalah pompa yang energi atau penggeraknya berasal dari hantaman air yang masuk ke dalam pompa melalui pipa. Masuknya air kedalam pompa harus berlangsung secara kontinyu, karena pompa ini tidak menggunakan BBM atau tanpa motor listrik. Sehingga pompa ini disebut juga "Pompa Air Tanpa Motor" (Motorless Waterpump). Pompa hidram memiliki kemampuan memindahkan air dari sumber air ke tempat yang lebih tinggi dari sumber air semula.

Dari studi literatur yang telah dilakukan, banyak hal yang mempengaruhi efektifitas kinerja dari pompa hidram, antara lain tinggi jatuh, diameter pipa, jenis pipa, karakteristik katub limbah dan panjang pipa pada katub limbah. Oleh karena itu perlu diwujudkan suatu persamaan atau rumus empiris yang dapat memudahkan perencana pembuat pompa hidram untuk merencanakan pompa hidram yang efektif dan efisien. Dalam penelitian ini, penulis melakukan penelitian untuk mengetahui "Pengaruh Jumlah Katup Hisap dan Katup Buang Terhadap Kinerja Pompa Hidram".

\subsection{Definisi Pompa Hidram}

Pompa hidram adalah sebuah pompa yang energi atau tenaga penggeraknya berasal dari tekanan atau hantaman air yang masuk ke dalam pompa melalui pipa. Untuk itu, masuknya air yang berasal dari sumber air ke dalam pompa harus berjalan secara kontinyu atau terus menerus agar pompa dapat terus bekerja. 


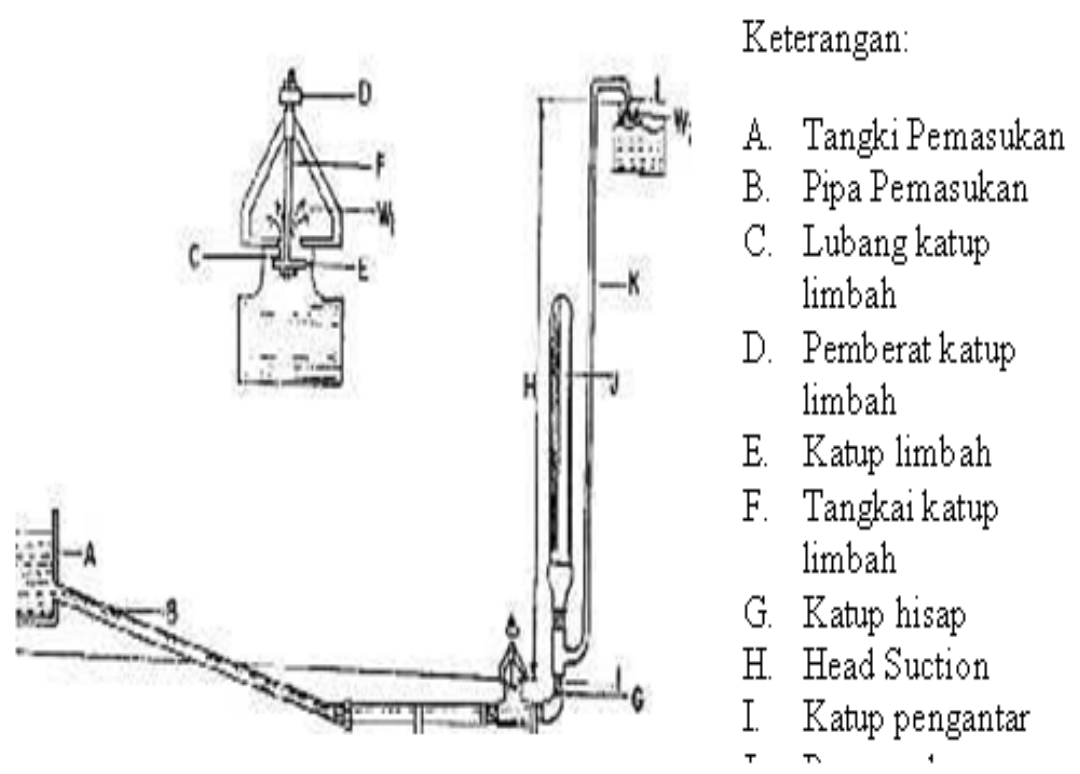

Gambar 1. Instalasi pompa hidram (Sumber: Hanafie dan De Longh, 1979)

Penggunaan pompa hidram tidak terbatas hanya pada penyediaan air untuk kebutuhan rumah tangga saja, tetapi juga dapat digunakan untuk memenuhi kebutuhan air pada sektor lainnya. Untuk itu, penggunaan pompa hidram dapat memberikan banyak manfaat, diantaranya:

a. Untuk mengairi sawah dan ladang ataupun areal perkebunan yang membutuhkan pasokan air secara kontinyu.

b. Untuk mengairi kolam dalam usaha perikanan.

c. Mampu menyediakan air untuk usaha peternakan.

d. Mampu memberi pasokan air untuk kebutuhan industri atau pabrik-pabrik pengolahan.

e. Air yang dihasilkan mampu menggerakan turbin yang berputar karena kekuatan air yang masuk dari pompa hidram, sehingga dapat menghasilkan listrik bila dihubungkan dengan generator.

\subsection{Komponen Utama Pompa Hidram dan Fungsinya}

Beberapa komponen utama sebuah pompa hidram adalah sebagai berikuti: Katup Limbah (Waste Valve)

Gambar 2. menunjukkan berbagai macam jenis katup limbah yang merupakan salah satu komponen terpenting pompa hidram. 


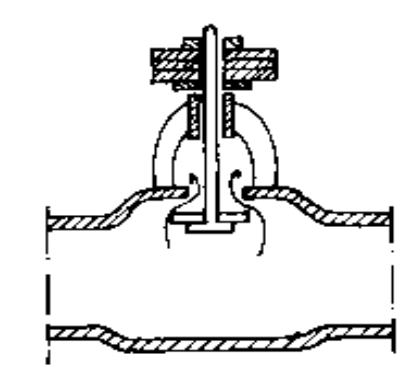

a. Katup Kardom Sederhana

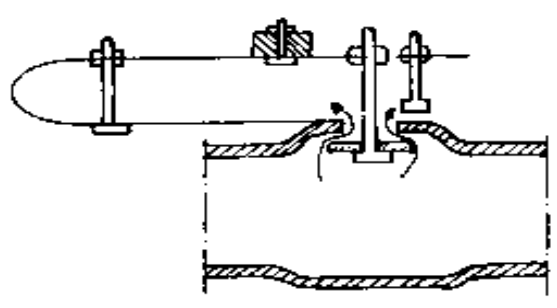

b. Katup Kardom Berpegas

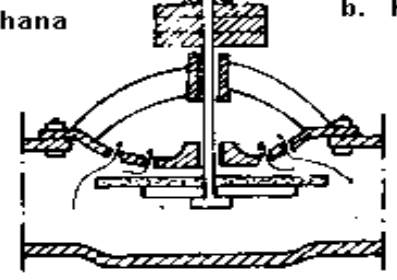

c. Katup Kardom Lentur

Gambar 2. Contoh Desain Katup Limbah (Hanafie dan De Longh, 1979)

Katup limbah dengan beban yang berat dan panjang langkah yang cukup jauh memungkinkan fluida mengalir lebih cepat, sehingga saat katup limbah menutup, akan terjadi lonjakan tekanan yang cukup tinggi, yang dapat mengakibatkan fluida kerja terangkat menuju tabung udara. Bagian - bagian sebuah katup limbah dapat dilihat pada Gambar 3.

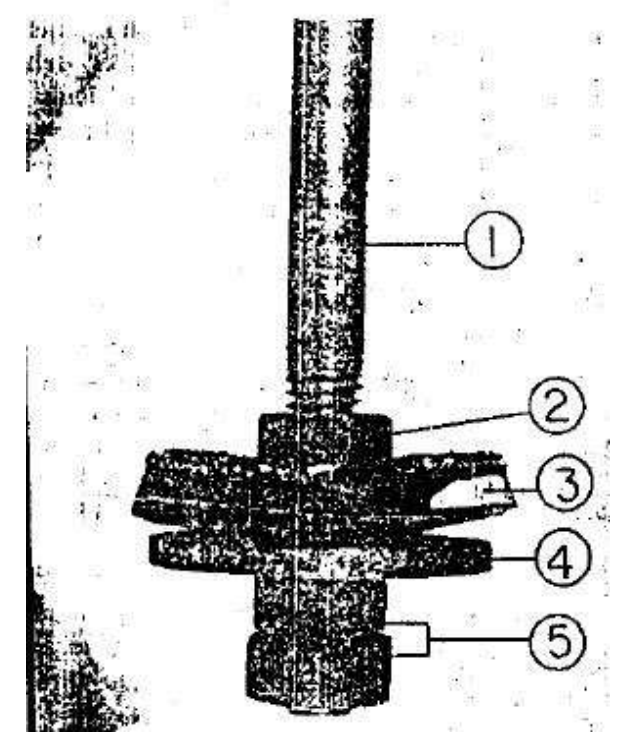

Gambar 3. Bagian - Bagian Katup Limbah. (Hanafie dan De Longh, 1979). Keterangan gambar: 1)Tangkai Katup; 2) Mur Penjepit Atas; 3) Karet Katup; 4) Plat Katup; 5)Mur Penjepit Bawah

Katup Penghantar (Delivery Valve)

Katup penghantar adalah sebuah katup satu arah yang berfungsi untuk menghantarkan air dari badan hidram menuju tabung udara untuk selanjutnya dinaikkan menuju tangki penampungan. Katup penghantar harus dibuat satu arah agar air yang 
telah masuk ke dalam tabung udara tidak dapat kembali lagi ke dalam badan hidram. Katup penghantar harus mempunyai lubang yang besar sehingga memungkinkan air yang dipompa memasuki ruang udara tanpa hambatan pada aliran (Hanafie dan De Longh, 1979).

Tabung Udara (Air Chamber)

Tabung udara digunakan untuk memampatkan udara di dalamnya dan untuk menahan tekanan dari siklus ram. Selain itu, dengan adanya tabung udara memungkinkan air melewati pipa penghantar secara kontinyu. Volume tabung udara dibuat sama dengan volume dari pipa penghantar.

Katup Udara (Air Valve)

Udara dalam tabung udara, secara perlahan - lahan akan ikut terbawa ke dalam pipa penghantar karena pengaruh turbulensi air. Akibatnya, udara dalam pipa perlu diganti dengan udara baru melalui katup udara.

Pipa Masuk (Driven Pipe)

Pipa masuk dirancang agar menahan tekanan tinggi yang disebabkan oleh menutupnya katup limbah secara tiba-tiba.

\subsection{Prinsip Kerja Pompa Hidram}

Mekanisme kerja pompa hidram adalah pelipat gandaan kekuatan pukulan sumber air yang merupakan input ke dalam tabung pompa hidram dan menghasilkan output air dengan volume tertentu sesuai dengan lokasi yang memerlukan. Dalam mekanisme ini terjadi proses perubahan energi kinetis berupa aliran air menjadi tekanan dinamis yang mengakibatkan timbulnya palu air, sehingga terjadi tekanan yang tinggi di dalam pipa. Dengan perlengkapan klep buang dan klep tekan yang terbuka dan tertutup secara bergantian, tekanan dinamik diteruskan ke dalam tabung udara yang berfungsi sebagai kompresor, yang mampu mengangkat air dalam pipa penghantar.

Cara kerja pompa hidram berdasarkan posisi klep buang dan variasi kecepatan fluida terhadap waktu, dapat dibagi menjadi 4 periode, seperti yang terlihat pada Gambar 4.

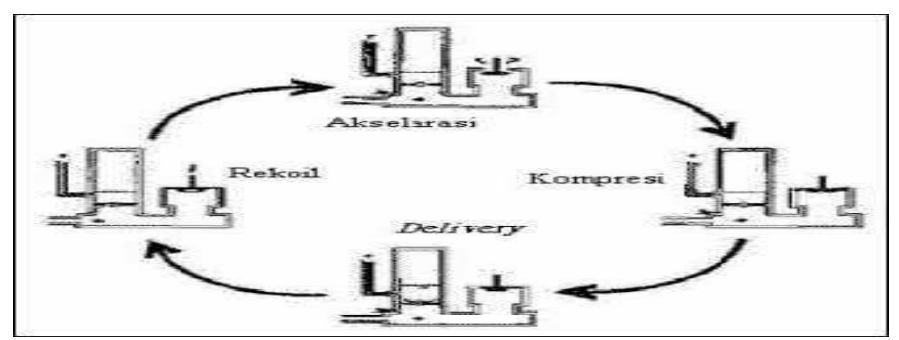

Gambar 4. Prinsip Kerja Pompa Hidram (Sumber:Suroso,2012)

Prinsip kerja dari pompa hidram dapat dilihat dari Gambar 5. 


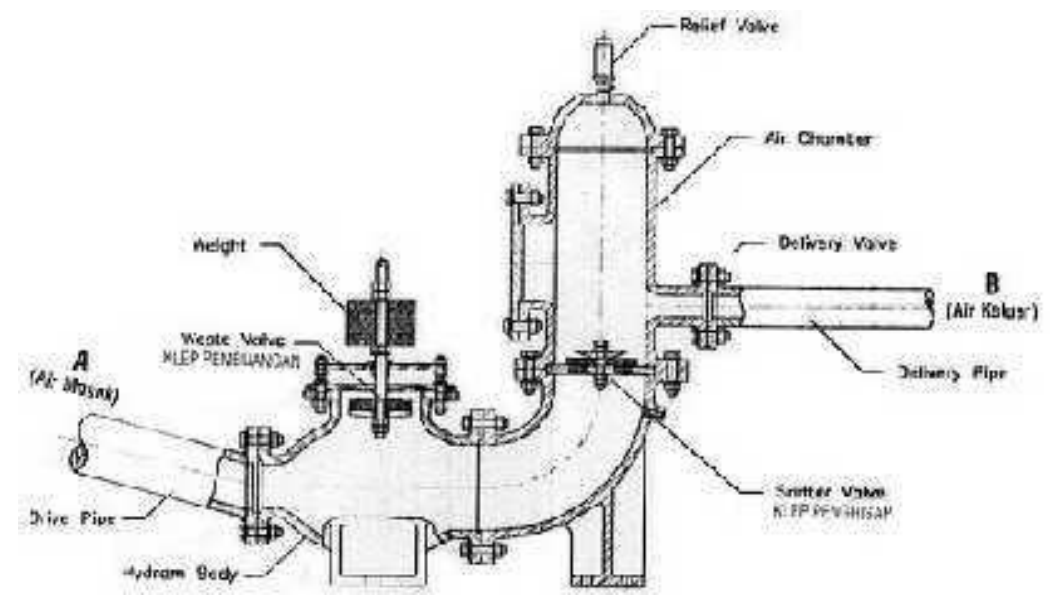

Gambar 5. Prinsip Kerja Pompa Hidram. Keterangan gambar: Periode 1: Akhir siklus yang sebelumnya, kecepatan air melalui ram bertambah, air melalui katup limbah yang sedang terbuka, timbul tekanan negatif yang kecil dalam hidram; Periode 2: Aliran bertambah sampai maksimum melalui katup limbah yang terbuka dan tekanan dalam pipa pemasukan juga bertambah secara bertahap; Periode 3: Katup limbah mulai menutup dengan demikian menyebabkan naiknya tekanan dalam hidram, kecepatan aliran dalam pipa pemasukan telah mencapai maksimum; Periode 4: Katup limbah tertutup, menyebabkan terjadinya palu air (water hammer) yang mendorong air melalui katup pengantar. Kecepatan aliran pipa pemasukan berkurang dengan cepat; Periode 5: Denyut tekanan terpukul ke dalam pipa pemasukan, menyebabkan timbulnya hisapan kecil dalam hidram. Katup limbah terbuka karena hisapan tersebut dan juga karena beratnya sendiri. Air mulai mengalir lagi melalui katup limbah dan siklus Hidram terulang kembali.

\subsection{Efisiensi Pompa Hidram.}

Ada dua metode dalam perhitungan efisiensi hidram, yaitu:

Menurut D' Aubuisson:

$$
\mu_{A}=\frac{q h}{(Q+q) H}
$$

Dengan:

$$
\begin{aligned}
\eta_{A} & =\text { efisiensi hidram menurut D'Aubuisson } \\
\mathrm{q} & =\text { debit keluar }\left(\mathrm{m}^{3} / \mathrm{s}\right) \\
\mathrm{Q} & =\text { debit limbah }\left(\mathrm{m}^{3} / \mathrm{s}\right) \\
\mathrm{h} & =\text { head keluar }(\mathrm{m}) \\
\mathrm{H} & =\text { head masuk }(\mathrm{m})
\end{aligned}
$$

Menurut Rankine:

$$
\mu_{R}=\frac{q(h-H)}{(Q+q)-H}
$$

\section{Dengan:}

$\eta_{A}=$ efisiensi hidram menurut D'Aubuisson 


$$
\begin{aligned}
\mathrm{q} & =\text { debit keluar }\left(\mathrm{m}^{3} / \mathrm{s}\right) \\
\mathrm{Q} & =\operatorname{debit} \operatorname{limbah}\left(\mathrm{m}^{3} / \mathrm{s}\right) \\
\mathrm{h} & =\operatorname{head} \operatorname{keluar}(\mathrm{m}) \\
\mathrm{H} & =\operatorname{head} \operatorname{masuk}(\mathrm{m})
\end{aligned}
$$

\section{Metode Penelitian}

\subsection{Alat dan Bahan}

Penelitian ini dilaksanakan pada bulan April sampai Juni 2016, di Laboratorium Mesin dan Energi Pertanian Program Studi Teknik Pertanian STIPER Kutai Timur. Bahan yang digunakan untuk membuat alat adalah Pipa PVC 1" 5 batang, Sambungan L 1" 8 buah, Sambungan T 1" 6 buah, Reduser 1" ke 4"2 buah, Sambungan Ulir 1" 6 buah, Pipa PVC 4" 1 meter, Penutup pipa PVC 4" 1 buah, Drum, Isolatop 10 buah, Lem pipa PVC. Alat yang digunakan dalam pengambilan data adalah 2 Unit Pompa Hidram, Stopwatch, Gelas ukur, Ember.

\subsection{Prosedur Penelitian}

Penelitian ini dilakukan dengan cara melakukan pengujian alat pada tinggi air masuk 2 meter. Setelah itu dilakukan pengambilan data terhadap debit air masuk, debit air keluar, dan tinggi air keluar (head suction). Data yang telah diperoleh selanjutnya akan di analisa guna untuk mengetahui pengaruh jumlah katup terhadap kinerja pompa hidram.

\section{Hasil dan Pembahasan}

\subsection{Desain Instalasi Pompa Hidram}
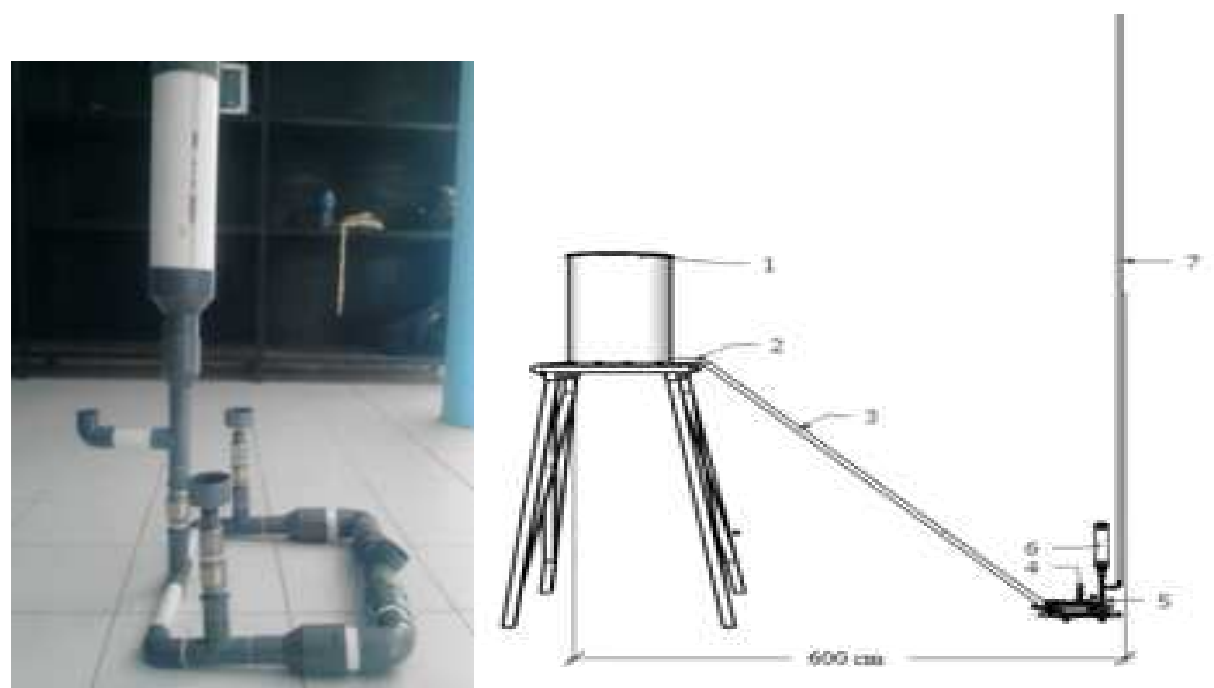

Gambar 6. Instalasi Pengujian Pompa Hidram

Prinsip kerja pompa hidram adalah dimulai dari air yang turun dari reservoir melalui pipa dengan kecepatan tertentu masuk kebadan pompa. Karena katub limbah yang berada dalam pompa yang awalnya terbuka, maka gerakan air dari reservoir tadi akan 
terpancing untuk melalui katub limbah. Dengan air dari reservoir yang mengalir terus menerus, maka tekanan dalam badan pompa akan meningkat, sehingga katub limbah akan tertutup. Hal ini akan mengakibatkan katub hantar terbuka akibat dari tekanan air dibadan pompa sehingga air akan naik dipipa hantar.

\subsection{Pengaruh Jumlah Katup terhadap Kapasitas Pemompaan}

Data rata-rata hasil pengamatan yang diperoleh selama pengujian, pengaruh jumlah katup terhadap kapasitas pemompaan dapat dilihat pada Tabel 1.

Tabel 1. Data Hasil Rata-rata Kapasitas Pemompaan

\begin{tabular}{|c|c|c|c|c|}
\hline \multirow[t]{2}{*}{ Jumlah Katup } & \multirow{2}{*}{$\begin{array}{c}\text { Tinggi } \\
\text { Air Keluar (m) }\end{array}$} & \multicolumn{2}{|c|}{ Debit Air Keluar(Q2) } & \multirow{2}{*}{$\begin{array}{c}\text { Kapasitas } \\
\text { Pemompaan }\left(\mathrm{m}^{3} / \mathrm{s}\right)\end{array}$} \\
\hline & & Waktu (s) & Volume $\left(\mathrm{m}^{3}\right)$ & \\
\hline 1 & 5 & 120 & $1,105.10^{-3}$ & $9,2083.10^{-6}$ \\
\hline 2 & 8 & 120 & $1,51.10^{-3}$ & $1,25833.10^{-5}$ \\
\hline 3 & 10 & 120 & $2,825.10^{-3}$ & $2,35416.10^{-5}$ \\
\hline
\end{tabular}

Berdasarkan Tabel 1. data hasil rata-rata kapasitas pemompaan menunjukkan bahwa jumlah katup berpengaruh terhadap kapasitas pemompaan, semakin banyak jumlah katup air yang masuk ke badan pompa semakin besar sehingga kapasitas pemompaan yang dihasilkan oleh pompa hidram semakin besar.

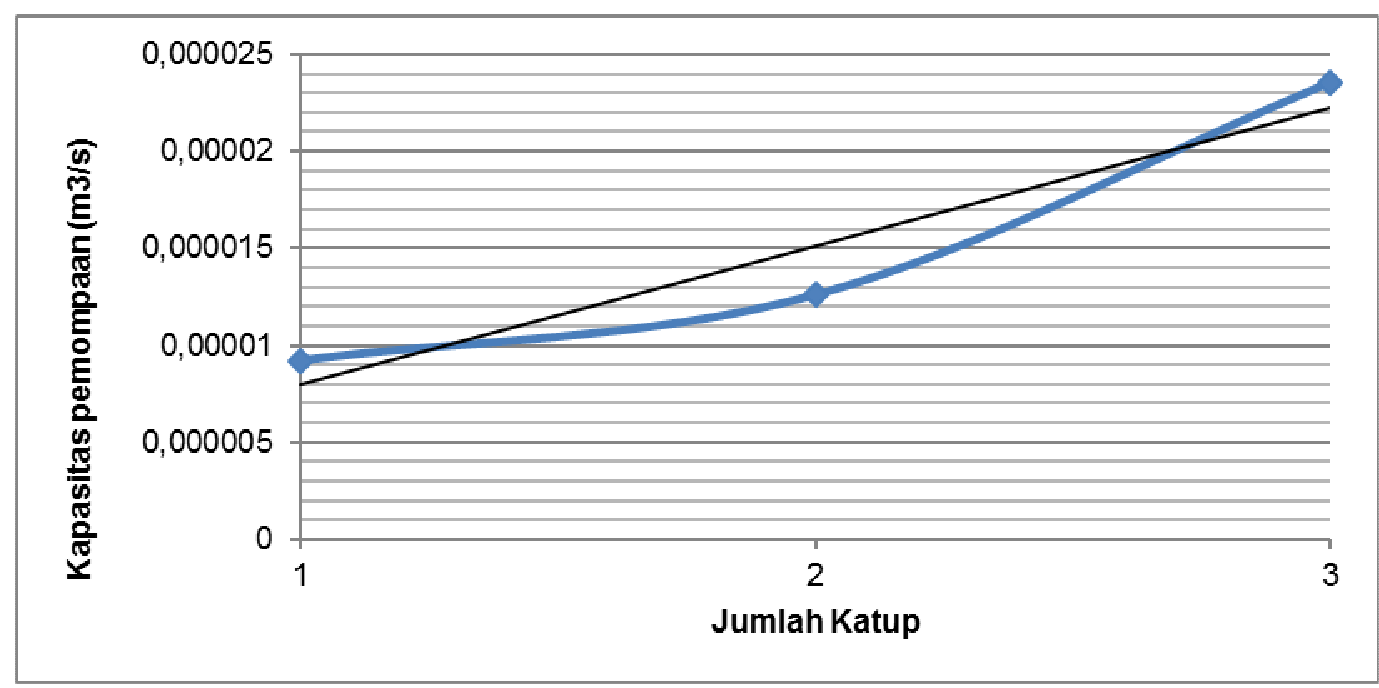

Gambar 7. Grafik Pengaruh jumlah katup terhadap Kapasitas Pemompaan.

Berdasarkan Gambar 7 dapat dilihat bahwa, kapasitas rata-rata hasil pemompaan tertinggi adalah pada jumlah katup 3 buah, dengan kapasitas rata-rata pemompaan sebesar $2,35416.10^{-5} \mathrm{~m}^{3} . \mathrm{s}^{-1}$ dengan head suction maksimum rata -rata yang dihasilkan 10 meter, mempunyai tekanan 29,400 N.m-2, dengan gaya $74,674 \mathrm{~N}$, dan energi potersial 98 Joule. Pada jumlah katup 2 buah, kapasitas rata-rata yang dihasilkan sebesar 1,25833.10${ }^{5} \mathrm{~m}^{3} \cdot \mathrm{s}^{-1}$, dengan head suction rata-rata yang dihasilkan 8 meter, mempunyai tekanan $19,600 \mathrm{~N} \cdot \mathrm{m}^{-2}$, dengan gaya 49,784 N, dan energi potensial 78,4 Joule. Sedangkan kapasitas pemompaan rata-rata terendah adalah pada jumlah katup 1 buah, dengan kapasitas rata-rata pemompaan $9,2083 \cdot 10^{-6} \mathrm{~m}^{3} \cdot \mathrm{s}^{-1}$ dengan head suction rata-rata yang 
dihasilkan 5 meter, mempunyai tekanan $9,800 ~ N . \mathrm{m}^{2}$, dengan gaya 24,892 N, dan energi potensial 49 Joule. Kurangnya kapasitas air yang dipompa disebabkan oleh kurangnya denyutan pada katup limbah, hal ini sesuai dengan pernyataan (Sofwan dan Siregar, 2015) yang menyatakan bahwa semakin sedikit denyutan katub limbah per menit maka semakin sedikit kapasitas air yang dipompa melalui pipa pengeluaran.

\subsection{Pengaruh Jumlah Katup terhadap Kapasitas Limbah}

Data rata-rata hasil pengamatan yang diperoleh selama pengujian, pengaruh jumlah katup terhadap kapasitas limbah dapat dilihat pada Tabel 2. Pada Tabel 2 terlihat bahwa semakin banyak jumlah katup, air yang masuk ke badan pompa semakin besar sehingga kapasitas limbah yang dihasilkan semakin besar.

Tabel 2. Data Hasil Rata-rata Kapasitas Limbah

\begin{tabular}{ccccc}
$\begin{array}{c}\text { Jumlah } \\
\text { Katup }\end{array}$ & $\begin{array}{c}\text { Tinggi Air Keluar } \\
(\mathrm{m})\end{array}$ & \multicolumn{2}{c}{ Debit Air Keluar (Q2) } & $\begin{array}{c}\text { Kapasitas } \\
\text { Limbah }\left(\mathbf{m}^{3} / \mathbf{s}\right)\end{array}$ \\
\hline 1 & 5 & 120 & $8,7.10^{-3}$ & $7,25.10^{-5}$ \\
\hline 2 & 8 & 120 & $1,13.10^{-2}$ & $9,41667.10^{-5}$ \\
\hline 3 & 10 & 120 & $1,41.10^{-2}$ & $1,175.10^{-4}$ \\
\hline
\end{tabular}

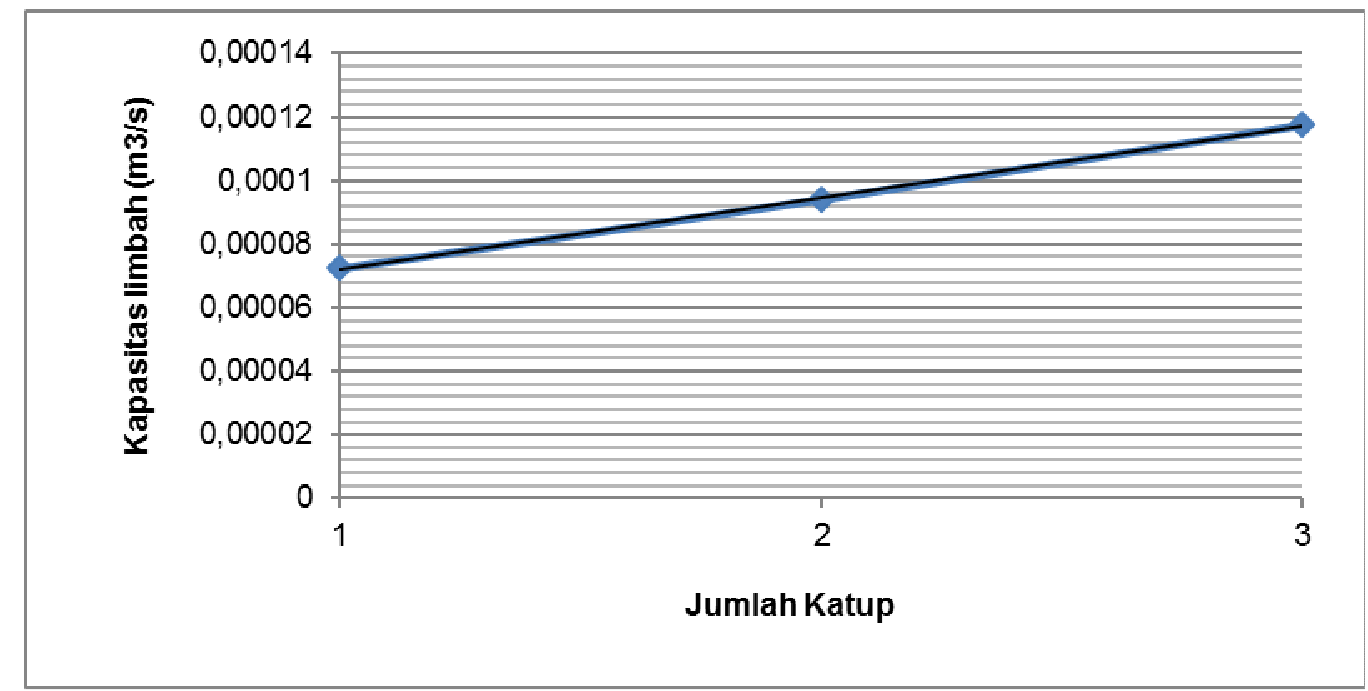

Gambar 8. Grafik pengaruh jumlah katup terhadap Kapasitas Limbah.

Berdasarkan Gambar 8, dapat dilihat bahwa kapasitas limbah rata-rata hasil pengujian tertinggi adalah pada jumlah katup 3 buah dengan kapasitas limbah rata-rata $1,175.10^{-4} \mathrm{~m}^{3} . \mathrm{s}^{-1}$, pada jumlah katup 2 buah kapasitas limbah rata-rata sebesar $9,41667.10^{-5} \mathrm{~m}^{3} \cdot \mathrm{s}^{-1}$, sedangkan kapasitas limbah rata-rata terendah adalah pada jumlah katup 1 buah, dengan kapasitas limbah rata-rata 7,25.10-4 $\mathrm{m}^{3} \cdot \mathrm{s}^{-1}$. Hal ini disebabkan karena semakin banyak jumlah katup, tekanan air yang masuk ke dalam badan pompa akan semakin besar, sehingga terjadi penutupan oleh katub limbah dan katub hisap 
secara bergantian, maka akan mengakibatkan banyaknya air yang terbuang melalui katub limbah selama proses pemompaan ( Sofwan dan Siregar, 2015).

\subsection{Pengaruh Jumlah Katup terhadap Kapasitas Total}

Data rata-rata hasil pengujian yang diperoleh selama pengujian, pengaruh jumlah katup terhadap kapasitas total dapat dilihat pada Tabel 3.

Tabel 3. Data Hasil Rata-rata Kapasitas Total

\begin{tabular}{ccccc}
$\begin{array}{c}\text { Jumlah } \\
\text { Katup }\end{array}$ & $\begin{array}{c}\text { Tinggi Air } \\
\text { Keluar } \\
(\mathrm{m})\end{array}$ & $\begin{array}{c}\text { Kapasitas } \\
\text { Pemompaan }\left(\mathrm{m}^{3} / \mathbf{s}\right)\end{array}$ & $\begin{array}{c}\text { Kapasitas } \\
\text { Limbah }\left(\mathrm{m}^{3} / \mathbf{s}\right)\end{array}$ & $\begin{array}{c}\text { Kapasitas } \\
\text { Total }\left(\mathbf{m}^{3} / \mathbf{s}\right)\end{array}$ \\
\hline 1 & 5 & $9,2083.10^{-6}$ & $7,25.10^{-5}$ & $9,09166.10^{-5}$ \\
\hline 2 & 8 & $1,25833.10^{-5}$ & $9,41667.10^{-5}$ & $1,319167.10^{4}$ \\
\hline 3 & 10 & $2,35416.10^{-5}$ & $1,175.10^{-4}$ & $2,116665.10^{-4}$
\end{tabular}

Pada Tabel 3. terlihat bahwa semakin banyak jumlah katup, air yang masuk ke badan pompa semakin besar sehingga kapasitas total yang dihasilkan akan semakin besar.

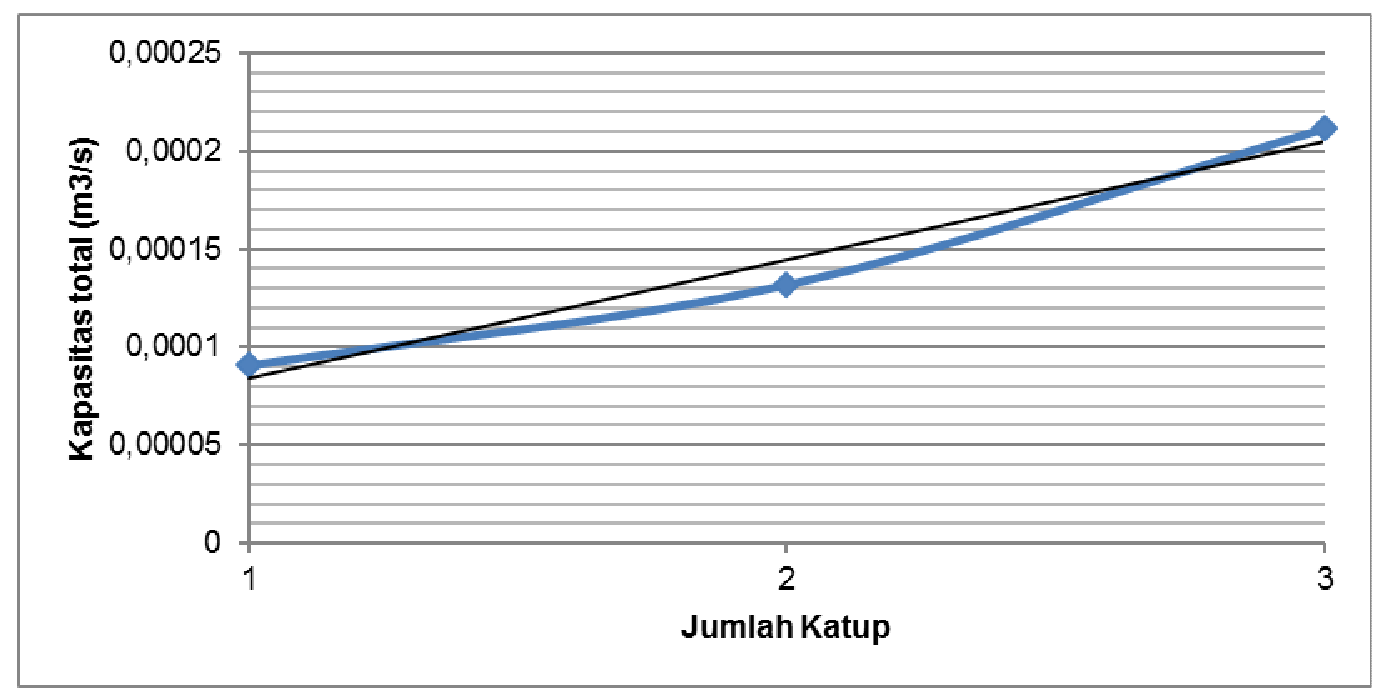

Gambar 9. Grafik Pengaruh Ketinggian terhadap Kapasitas Total

Berdasarkan Gambar 9 diatas, dapat dilihat bahwa kapasitas total rata-rata hasil pengujian tertinggi adalah pada jumlah katup 3 buah dengan kapasitas total rata-rata $2,116665.10^{-4} \mathrm{~m}^{3} \cdot \mathrm{s}^{-1}$, jumlah katup 2 buah kapasitas total rata-rata sebesar $1,319167.10^{4}$ $\mathrm{m}^{3} \cdot \mathrm{s}^{-1}$, dan kapasitas total rata-rata terendah adalah pada jumlah katup 1 buah dengan kapasitas rata-rata $9,09166 \cdot 10^{-5} \mathrm{~m}^{3} \cdot \mathrm{s}^{-1}$. Hal ini disebabkan karena apabila tekanan air yang masuk kebadan pompa semakin besar, maka katub limbah akan sering mengalami penutupan secara bergantian dengan katub hisap selama pemompaan. Hal ini yang mengakibatkan air terus keluar melalui katub limbah dan sebagian keluar melalui pipa pengeluaran. (Widarto dan Sudarto, 1997).

\subsection{Pengaruh Jumlah Katup Terhadap Efisiensi Pompa}


Data rata-rata hasil pengamatan yang diperoleh selama pengujian, pengaruh jumlah katup terhadap efisiensi pompa dapat dilihat pada Tabel 4

Tabel 4 : Efisiensi rata-rata pompa.

\begin{tabular}{ccccc}
$\begin{array}{c}\text { Jumlah } \\
\text { Katup }\end{array}$ & $\begin{array}{c}\text { Tinggi Air } \\
\text { Keluar } \\
(\mathrm{m})\end{array}$ & $\begin{array}{c}\text { Kapasitas } \\
\text { Pemompaan }\left(\mathbf{m}^{3} / \mathbf{s}\right)\end{array}$ & $\begin{array}{c}\text { Kapasitas } \\
\text { Limbah }\left(\mathbf{m}^{3} / \mathbf{s}\right)\end{array}$ & $\begin{array}{c}\text { Efisiensi } \\
\text { D' Aubuission(\%) }\end{array}$ \\
\hline 1 & 5 & $9,2083.10^{-6}$ & $7,25.10^{-5}$ & 6,0000725 \\
\hline 2 & 8 & $1,25833.10^{-5}$ & $9,41667.10^{-5}$ & 10,20 \\
\hline 3 & 10 & $2,35416.10^{5}$ & $1,175.10^{-4}$ & 16,0003525 \\
\hline
\end{tabular}

Pada Tabel 4. terlihat bahwa semakin banyak jumlah katup, maka semakin besar efisiensi volumetris yang dihasilkan oleh pompa.

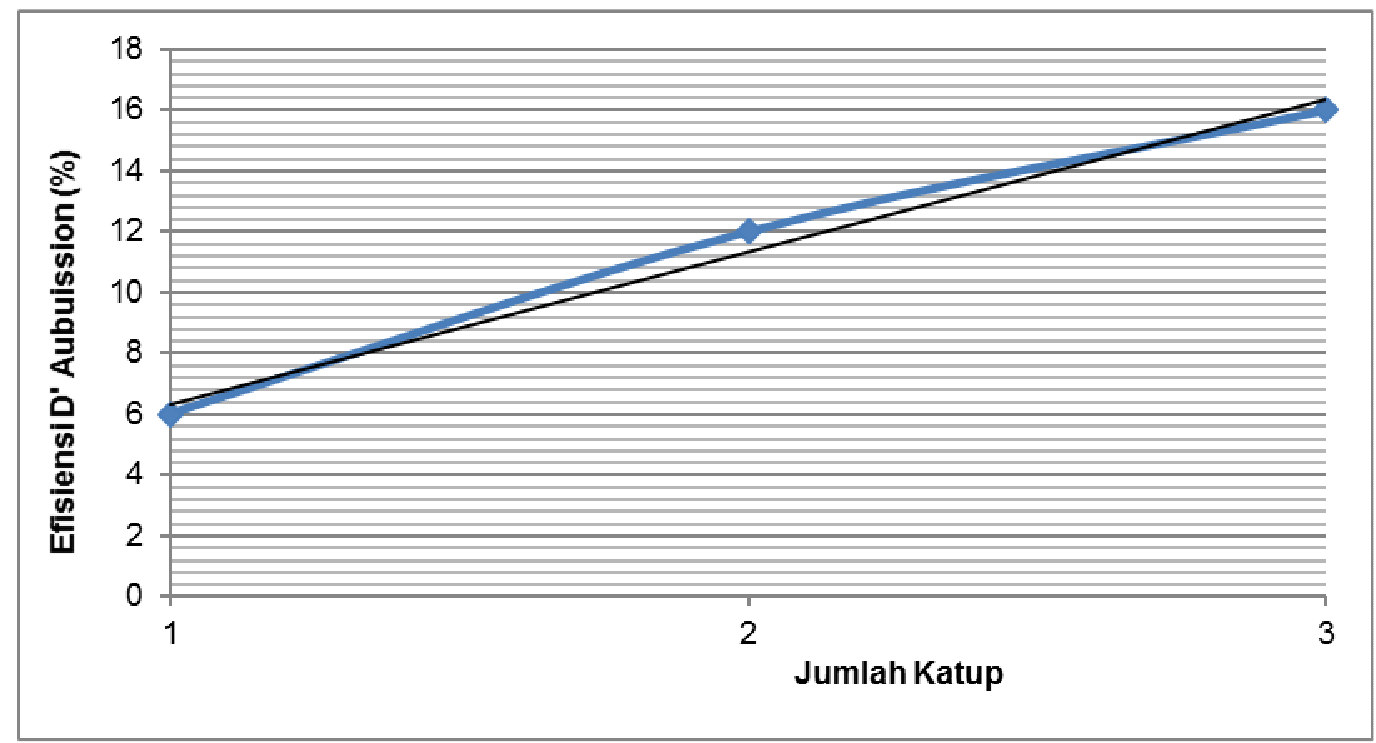

Gambar 10. Grafik Pengaruh Jumlah Katup terhadap Efisiensi Pompa

Berdasarkan Gambar 10. dapat dilihat bahwa efisiensi volumetris rata-rata hasil pengujian tertinggi adalah pada jumlah katup 3 buah, dengan efisiensi volumetrik rata-rata sebesar $16,0003525 \%$, dengan kapasitas pemompaan rata-rata yang dihasilkan sebesar $2,35416.10^{-5} \mathrm{~m}^{3} \cdot \mathrm{s}^{-1}$, kapasitas limbah rata-rata yang dihasilkan sebesar $1,175.10^{-4} \mathrm{~m}^{3} \cdot \mathrm{s}^{-1}$, dan head suction rata-rata yang dihasilkan 10 meter. Pada kondisi ini kapasitas pemompaan yang dihasilkan oleh pompa besar, kinerja dari pompa hidram juga maksimum, sehingga efisiensi pompa juga maksimum (Sofwan dan Siregar. 2015 ). Pada pengujian dengan jumlah katup 2 buah, efisiensi volumetrik rata-rata sebesar 10,20\%, dengan kapasitas pemompaan rata-rata yang dihasilkan sebesar $1,25833.10^{-5} \mathrm{~m}^{3} \cdot \mathrm{s}^{-1}$, dan kapasitas limbah rata-rata yang dihasilkan sebesar $9,41667.10^{-5} \mathrm{~m}^{3} \cdot \mathrm{s}^{-1}$, dengan head suction rata-rata yang dihasilkan 8 meter. Sedangkan, efisiensi pompa rata-rata terendah adalah pada pengujian dengan jumlah katup 1 buah, efisiensi volumetris ratarata sebesar 6,0000725\%, kapasitas pemompaan rata-rata yang dihasilkan sebesar $2,083 \cdot 10^{-6} \mathrm{~m}^{3} \cdot \mathrm{s}^{-1}$, dan kapasitas limbah rata-rata yang dihasilkan sebesar $7,25 \cdot 10^{-5} \mathrm{~m}^{3} \cdot \mathrm{s}^{-}$ ${ }^{1}$, dengan head suction rata-rata yang dihasilkan 5 meter. 
Jumlah katup berpengaruh terhadap knerja pmpa hidram, pengujian dengan 3 Katup: kapasitas rata-rata pemompaan sebesar $2,35416.10^{-5} \mathrm{~m}^{3} \cdot \mathrm{s}^{-1}$, head suction maksimum rata -rata yang dihasilkan 10 meter, dan efisiensi volumetrik rata-rata sebesar $16,0003525 \%$. Pengujian dengan 2 Katup: kapasitas rata-rata yang dihasilkan sebesar $1,25833.10^{-5} \mathrm{~m}^{3} \cdot \mathrm{s}^{-1}$, head suction rata-rata yang dihasilkan 8 meter, dan efisiensi volumetris rata-rata sebesar 10,20 \%. Pengujian dengan 1 Katup: kapasitas rata-rata pemompaan $9,2083 \cdot 10^{-6} \mathrm{~m}^{3} \cdot \mathrm{s}^{-1}$, head suctionrata-rata yang dihasilkan 5 meter, efisiensi volumetris rata-rata sebesar $6,0000725 \%$.

\section{Daftar Pustaka}

Hanafie, J. dan H. De Longh 1979. Teknologi pompa hidraulik RAM : buku petunjuk untuk pembuatan dan pemasangan. Pusat Teknologi Pembangunan Institut Teknologi Bandung, Bandung.

Sofwan, M. dan I. H. Siregar. 2015. Pengaruh Ketinggian Terjunan dan Volume Tabung Udara terhadap Kinerja Pompa Hidram. Jurnal Teknik Mesin, Vol. 3(03): hal. $16-24$.

Suarda, M. dan I. K. G. Wirawan. 2008. Kajian eksperimental pengaruh tabung udara pada head tekanan pompa hidram. Jurnal IImiah Teknik Mesin CAKRAM, Vol. 2(1): hal. $10-14$.

Suroso, 2012. Membuat Pompa Hidram. Kanisius, Yogyakarta.

Taye, T. 1998. Hydraulic Ram Pump. Journal of the ESME, Vol II, No. 1

Widarto dan Sudarto 1997. Membuat Pompa Hidram. Kanisius, Jakarta. 